\title{
PHOTOCATALYTIC DEGRADATION OF TNT FROM WATER IN UV-VIS/Fe-TiO 2 SYSTEM
}

Ines Nitoi ${ }^{1}$, Petruta Oancea ${ }^{2}$, Lucian Alexandru Constantin ${ }^{1}$, Maria Crisan ${ }^{3}$, Dorel Crisan $^{3}$,Ionut Cristea ${ }^{1,4}$, Mirela Alina Constantin ${ }^{1}$

${ }^{1}$ National Research and Development Institute for Industrial Ecology - ECOIND, 7173 Drumul Podu Dambovitei St., 060652, Bucharest, Romania

2 Faculty of Chemistry, University of Bucharest, 4-12 Elisabeta Av., 030016, Bucharest, Romania

3 Ilie Murgulescu Institute of Physical Chemistry, Romanian Academy, 202 Splaiul Independentei, 060021, Bucharest, Romania

4 Faculty of Applied Chemistry and Materials Science, University Politehnica of Bucharest, 1-7 Gheorghe Polizu St., 011061, Bucharest, Romania

\begin{abstract}
2,4,6-Trinitrotoluene(TNT) is one of most common toxic pollutant identified in wastewater generated from ammunitions plants. Due to its potential carcinogenic characteristics, TNT presence in water bodies represents a risk for human health and aquatic life. Among modern treatment methods, $\mathrm{TiO}_{2}$ photocatalysis was successfully applied in order to remove toxic pollutants. $\mathrm{Fe}^{-\mathrm{TiO}_{2}}$ assisted photocatalytic degradation of TNT in aqueous media, under UV-VIS irradiation was studied. The effects of operating parameters on photocatalytic process performances, kinetic and mechanism of pollutant degradation were investigated. Solutions with (0.27-2.72) x 10-4 M TNT content were photo-oxidized using a medium pressure Hg lamp as UV-VIS light source $(\lambda=320-550 \mathrm{~nm})$, in the following working conditions: $\mathrm{pH}=7$; photocatalyst dose = $50-500 \mathrm{mg} / \mathrm{L}$; irradiation time $=30-240 \mathrm{~min}$. Prior to irradiation, the photocatalyst was added to samples, and resulted suspension was bubbled with air (50 L/h). In order to evaluate the effect of the main active species involved in $\mathrm{Fe}^{-\mathrm{TiO}_{2}}$ assisted photocatalytic degradation of TNT we suppressed the free $\cdot \cdot \mathrm{OH}$ radicals mediated process by addition of $16 \times 10^{-3} \mathrm{M}$ iso-propanol (i-PrOH) scavenger. Lock of $\cdot \mathrm{OH}_{\text {ads }}$ radicals' production on the catalyst surface was assured by addition of $16 \times 10^{-3} \mathrm{M}$ sodium iodide ( $\mathrm{Nal}$ ). The initial and irradiated samples were analysed for $\mathrm{TNT}^{-\mathrm{NO}_{3}}$, $\mathrm{NO}_{2}{ }^{-}$and $\mathrm{NH}_{4}{ }^{+}$concentrations by Gas Chromatography (GC), and lon Chromatography respectively. In the tested experimental conditions, at $2.72 \times 10^{-4} \mathrm{M}$ pollutant concentration, the increase of catalyst load up to $200 \mathrm{mg} / \mathrm{L}$ leads to the enhancement of initial TNT degradation rate up to $0.64 \times 10^{-7} \mathrm{Ms}^{-1}$. Since, ten times increase of initial TNT content has a negative effect on pollutant degradation rate constant, in similar experimental condition, prolonged irradiation time from 60 to 240 min was needed in order to assure pollutant advanced degradation efficiencies $(\geq$ 99.9\%). The TNT degradation and its inorganic by-products formation obeyed a pseudo-first-order kinetics. The experimental results of the reactive species quenching showed that $\cdot \mathrm{OH}$ radicals was the predominant oxidant species participated in reaction, and the pollutant degradation occurred mainly on the surface of catalyst.
\end{abstract}

Keywords: 2,4,6-Trinitrotoluene, $\mathrm{Fe}-\mathrm{TiO}_{2}$ photocatalyst, AOPs 


\section{Introduction}

2,4,6-Trinitrotoluene(TNT) is one of most common toxic pollutant identified in wastewater generated from ammunitions plants. Due to its potential carcinogenic characteristics, TNT presence in water bodies represents a risk for human health and aquatic life [1]. These reasons, imposed inclusion of TNT on the list of priority pollutants which are strictly regulated in EU countries.

Although, the major route of natural TNT degradation in aquatic environment is photolysis, with a half-time about 70 days [2], partial aromatic ring cleavage and pure mineralization is asking for implementation of powerful treatment methods in order to assure an adequate pollutant removal. In the last decade, advanced oxidation processes (AOPs) have been proved to be effective for destruction of refractory toxic pollutants [3]. Several researchers studied the mineralization of nitroaromatic compounds using UV/Fenton's reagent [4,5] or $\mathrm{UV} / \mathrm{H}_{2} \mathrm{O}_{2}$ technique [6,7]. Li et al. investigated the conversion of 2,4,6-TNT by Fenton's reagent, in which higher oxidation efficiency was obtained at $\mathrm{pH} 3.0$ [8]. Some other publications have been focussed on the decomposition of 2,6-DNT through ozonation, $\mathrm{H}_{2} \mathrm{O}_{2} / \mathrm{O}_{3}$ or $\mathrm{UV} / \mathrm{O}_{3}$ methods $[9,10]$. Beside these photo induced techniques, semiconductor photocatalysis has been proved to be effective in degradation of nitroaromatics [11]. Among various semiconductors, titania was a widely studied photocatalyst, due to its chemical inertness, low cost, photostability and non-toxicity $[12,13]$. However, $\mathrm{TiO}_{2}$ is only photoactive under UV light irradiation due to its wide band gap energy (3.2 eV: anatase).

Therefore, the modification of semiconductor aimed to reduce the photocatalyst band gap and increase its quantum efficiency in visible domain represents an important issue. One feasible approach consists in doping oxide semiconductor with metal, which allows extending the light absorption of photocatalyst in visible region [14]. Also, it is experimentally found that the presence of iron in $\mathrm{Fe}-\mathrm{TiO}_{2}$ catalysts enhances the photocatalytic activity of $\mathrm{TiO}_{2}$ by acting both as hole and electron traps [15].

$0.5 \% \mathrm{Fe}^{-\mathrm{TiO}_{2}}$ assisted photocatalytic degradation of TNT in aqueous media, under UV-VIS irradiation was studied. The effects of operating parameters such as catalyst loading, pollutant concentration and irradiation time were assessed. The kinetic and mechanism of pollutant degradation were also investigated.

\section{Experimental}

The photo-degradation experiments were performed in a batch reactor equipped with cooling system and a medium pressure $\mathrm{Hg}$ lamp as UV-VIS light source $(\lambda=320-550$ $\mathrm{nm})$. Solutions with $(0.27-2.72) \times 10^{-4} \mathrm{M}$ TNT content were photo-oxidized in the following working conditions: $\mathrm{pH}=7$; photocatalyst dose $=50-500 \mathrm{mg} / \mathrm{L}$; irradiation time $=30-240 \mathrm{~min}$. Prior to irradiation, the photocatalyst was added to samples, and resulted suspension was bubbled with air $(50 \mathrm{~L} / \mathrm{h})$.

In order to evaluate the effect of the main active species involved in $\mathrm{Fe}-\mathrm{TiO}_{2}$ assisted photocatalytic degradation of TNT we suppressed the free $\cdot \mathrm{OH}$ radicals mediated process by addition of $16 \times 10^{-3} \mathrm{M}$ iso-propanol (i-PrOH) scavenger. Lock of $\cdot \mathrm{OH}_{\text {ads }}$ radicals' production on the catalyst surface was assured by addition of $16 \times 10^{-3} \mathrm{M}$ sodium iodide ( $\mathrm{Nal}$ ). The initial and irradiated samples were analysed for TNT and inorganic nitrogen $\left(\mathrm{Ninorg}=\mathrm{N}-\mathrm{NO}_{3}{ }^{-}+\mathrm{N}-\mathrm{NO}_{2}{ }^{-}+\mathrm{N}-\mathrm{NH}_{4}{ }^{+}\right.$) concentrations by Gas Chromatography (GC), and lon Chromatography (IC) respectively. 


\section{Results and discussions}

\section{Effect of photocatalyst loading}

A series of experiments were carried out on TNT solution with $2.72 \times 10^{-4} \mathrm{M}$ content at $\mathrm{pH}=7$, by varying the $0.5 \% \mathrm{Fe}-\mathrm{TiO}_{2}$ photocatalyst dose between $50-500 \mathrm{mg} / \mathrm{L}$. For each photocatalyst dose, TNT initial degradation rates $\left(r_{0}\right)$ were calculated at $30 \mathrm{~min}$ irradiation times. The results presented in Figure 1 shows that ro values increases up to $0.64 \times 10^{-7} \mathrm{Ms}^{-1}$ by increasing the catalyst dose from 50 to $200 \mathrm{mg} / \mathrm{L}$. Increase of catalyst loading above $200 \mathrm{mg} / \mathrm{L}$ leads to degradation rate decrease. Thus, a value of $\mathrm{r}_{0}=0.41 \times 10^{-7} \mathrm{Ms}^{-1}$ was calculated at $500 \mathrm{mg} / \mathrm{L}$ dose. The enhancement of TNT initial degradation rate with catalyst loading was due to the increases in the surface area of the catalyst available for pollutant adsorption and degradation. Higher values than optimum catalyst dose $(200 \mathrm{mg} / \mathrm{L})$ increase the solution turbidity leading to decrease in the penetration depth of light into suspension and in the degradation rate $[16,17]$. In all subsequent experiments the optimum catalyst loading of $200 \mathrm{mg} / \mathrm{L}$ was applied.

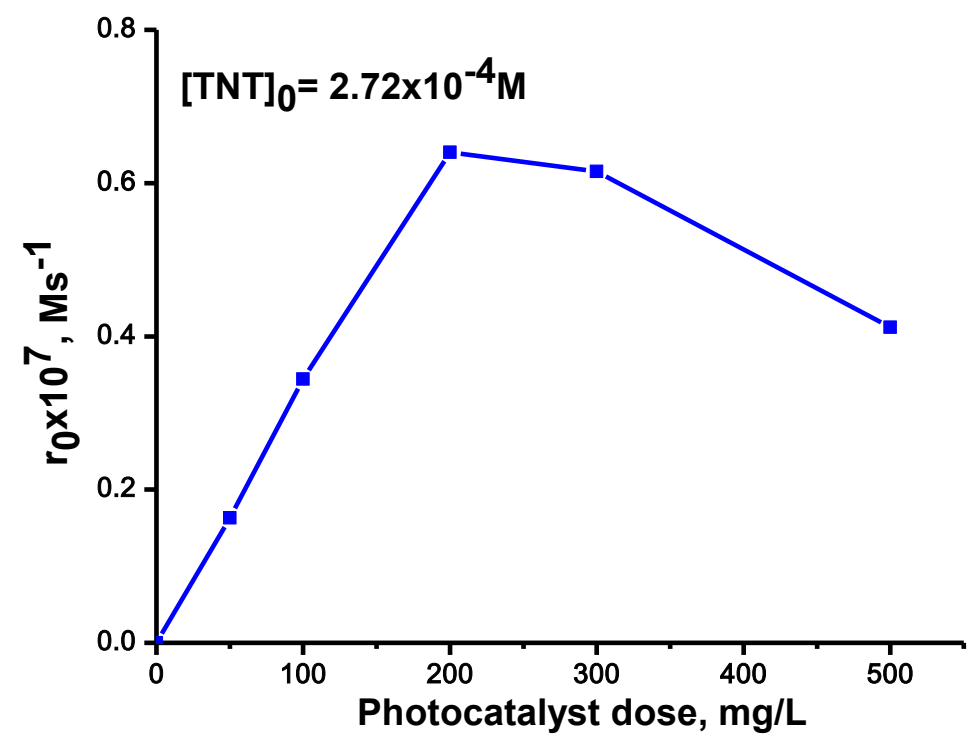

Figure 1 Evolution of TNT initial degradation rate $\left(r_{0}\right)$ versus photocatalyst dose

\section{Effects of TNT initial concentration and irradiation time}

Since TNT concentration in real aqueous systems varies, it was necessary to assess the influence of these parameters on pollutant conversion efficiency in order to set up the optimum working conditions which assure TNT advanced degradation.

The experiments were carried out on four different initial TNT concentration, situated between (0.27-2.72) x $10^{-4} \mathrm{M}$, using established photocatalyst optimum dose, at $\mathrm{pH}=7$ and various irradiation times (30-240 $\mathrm{min})$. Experimental results are presented in the following table. 
Table 1 Influence of initial TNT concentration and irradiation time on pollutant degradation and organic nitrogen mineralization by photocatalysis using $200 \mathrm{mg} / \mathrm{L} \quad 0.5 \% \mathrm{Fe}-\mathrm{TiO}_{2}$ catalyst

\begin{tabular}{|c|c|c|c|c|}
\hline $\begin{array}{c}\text { Irradiation } \\
\text { time(min) }\end{array}$ & $\begin{array}{c}\text { TNTx10 } \\
(\mathbf{M})\end{array}$ & $\begin{array}{c}\mathbf{N}_{\text {inorg }} \mathbf{x} \mathbf{1 0}^{\mathbf{4}} \\
(\mathbf{M})\end{array}$ & $\begin{array}{c}\mathbf{\eta}_{\text {TNT }} \\
(\%)\end{array}$ & $\begin{array}{c}\boldsymbol{\eta}_{\text {Ninorg }} \\
(\%)\end{array}$ \\
\hline 0 & 0.270 & $0.816^{*}$ & 0 & 0 \\
\hline 30 & 0.107 & 0.149 & 60.37 & 18.39 \\
\hline 60 & 0.025 & 0.282 & 90.74 & 34.81 \\
\hline 120 & 0.003 & 0.463 & 98.89 & 57.16 \\
\hline 180 & 0.0003 & 0.576 & 99.89 & 71.11 \\
\hline 0 & 0.780 & $2.340^{*}$ & 0 & 0 \\
\hline 30 & 0.368 & 0.750 & 52.82 & 13.85 \\
\hline 60 & 0.168 & 1.532 & 78.46 & 25.00 \\
\hline 120 & 0.032 & 3.200 & 95.89 & 42.87 \\
\hline 180 & 0.008 & 4.536 & 98.97 & 59.19 \\
\hline 240 & 0.002 & 6.048 & 99.76 & 69.10 \\
\hline 0 & 1.500 & $4.500^{*}$ & 0 & 0 \\
\hline 30 & 0.776 & 0.659 & 48.27 & 12.27 \\
\hline 60 & 0.424 & 1.264 & 71.73 & 20.39 \\
\hline 120 & 0.100 & 2.700 & 93.33 & 40.56 \\
\hline 180 & 0.026 & 4.061 & 98.27 & 54.53 \\
\hline 240 & 0.007 & 5.414 & 99.53 & 65.04 \\
\hline 0 & 2.72 & $8.160^{*}$ & 0 & 0 \\
\hline 30 & 1.566 & 0.553 & 42.43 & 12.80 \\
\hline 60 & 0.901 & 1.105 & 66.87 & 19.70 \\
\hline 120 & 0.298 & 2.210 & 89.04 & 37.69 \\
\hline 180 & 0.089 & 3.415 & 96.72 & 40.55 \\
\hline 240 & 0.019 & 4.960 & 99.3 & 59.33 \\
\hline
\end{tabular}

*Organic nitrogen concentration corresponding to TNT initial concentration

Under the same working conditions remanent pollutant concentration in irradiated samples increases with TNT initial concentration due to the competition between the organic degradation by-products and parent pollutant for the photo-generated species resulted by UV-VIS excitation of $0.5 \% \mathrm{Fe}-\mathrm{TiO}_{2}$ catalyst. This species, like $\cdot \mathrm{OH}$ radicals and electrons are involved in oxidation and reduction reactions leading to organic pollutants conversion down to their mineralization. As result, at 60 min irradiation, ten times increasing of initial TNT concentration from $0.27 \times 10^{-4} \mathrm{M}$ to $2.72 \times 10^{-4} \mathrm{M}$ leads to decrease of TNT degradation efficiencies (nTNT) from 91 to 67\%. A similar behaviour is observed in respect to organic nitrogen mineralization efficiencies ( $n_{\text {Ninorg}}$ ) which decrease from 35 to $20 \%$. The lower level of nitrogen mineralization compared with pollutant degradation is related to generation of nitrogen containing organic byproducts during TNT degradation.

The negative effect of initial pollutant concentration increase on its degradation efficiency can be diminished by prolonging irradiation time, due to increase of photonic energy absorbed by catalyst which assures higher concentrations of photo-generated - $\mathrm{OH}$ radicals and electrons, enhancing pollutant degradation efficiency. Thus, in the case of $0.27 \times 10^{-4} \mathrm{M}$ TNT initial concentration, prolonged irradiation time of $180 \mathrm{~min}$ assures the increase of pollutant degradation and organic nitrogen mineralization up to 99 and $71 \%$, respectively. Comparable pollutant degradation efficiency was registered for $2.72 \times 10^{-4} \mathrm{M}$ TNT initial concentration, but only for 240 min irradiation time, while organic nitrogen mineralization efficiency does not exceed $60 \%$. 


\section{Kinetics and mechanism of TNT photocatalytic degradation}

Using experimental data presented in Table 1, the kinetic curves in respect with pollutant degradation and organic nitrogen mineralization were draw. These curves were linearized by a kinetic equation of pseudo-first order. In the Figure 2 are illustrated the kinetic equations for an initial TNT concentration of $2.72 \times 10^{-4} \mathrm{M}$. The rate constants for each pollutant initial concentration were calculated from the slops of linear plots. The $\mathrm{k}^{\prime}$ TNT and $\mathrm{k}^{\prime}$ Ninorg values decreased from $6.13 \times 10^{-4}$ to $3.4 \times 10^{-4} \mathrm{~s}^{-1}$ and from $1.16 \times 10^{-4}$ to $0.59 \times 10^{-4} \mathrm{~s}^{-1}$ respectively, for TNT initial concentration increasing between $0.27 \times 10^{-4}$ and $2.72 \times 10^{-4} \mathrm{M}$.

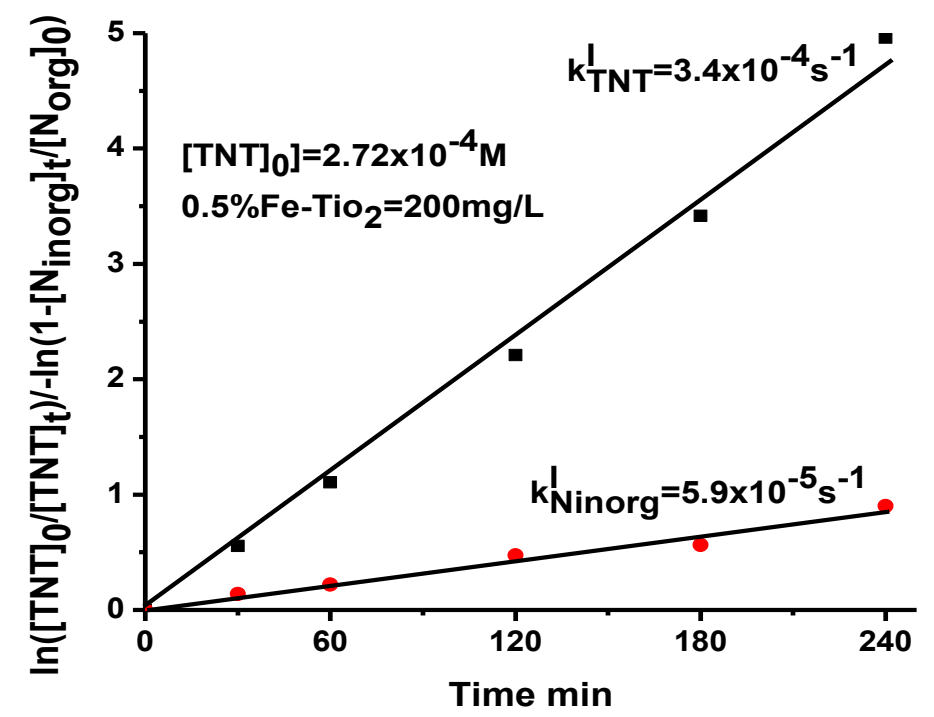

Figure 2. The pseudo-first order kinetics of TNT degradation and organic nitrogen mineralization

It is well known that understanding the mechanism of the oxidizing species generated at the irradiated catalyst interface, is essential for elucidating the mechanism of pollutant photocatalysis. Alcohols like iso-propanol (i-PrOH) are usually used as a diagnostic tool of $\cdot \mathrm{OH}$ radicals mediated mechanism. To confirm the role of surface bound or free $\cdot \mathrm{OH}$ radicals in the degradation mechanism, the photocatalytic experiments were carried out in the presence of $\mathrm{Nal}$, a well-known surface $\cdot \mathrm{OH}$ radical scavenger, as well as $\mathrm{i}-\mathrm{PrOH}$, a free $\cdot \mathrm{OH}$ radical scavenger [18]. Besides, iodide ion is an excellent scavenger of hole which is easily captured by $\mathrm{I}^{-}$and pathways due to oxidation by surface $\bullet \mathrm{OH}$ radical are hindered [19]. As is presented in Figure 3 , the rate of TNT degradation significantly decrease with $\mathrm{Nal}$ addition, indicating the crucial role of surface $\cdot \mathrm{OH}$ radicals pathways. It should be emphasized that addition of $\mathrm{Nal}$ to the system allows TNT to react with $\mathrm{O}_{2}{ }^{\circ}$ radicals, resulted from reaction of electrons with dissolved $\mathrm{O}_{2}$ (the experiments were performed under air bubbling), in the absence of surface $\cdot \mathrm{OH}$ radicals which is a minor reaction pathway. However, it can be seen from Figure 3 that adding of i-PrOH had smaller inhibitory effect on pollutant degradation rate than $\mathrm{Nal}$, implying that free $\cdot \mathrm{OH}$ radicals were not majorly involved in the TNT photodegradation process. The results showed that the surface $\cdot \mathrm{OH}_{\text {ads }}$ radicals were probably responsible for the degradation of TNT rather than $\bullet \mathrm{OH}_{\text {free }}$ radicals. 


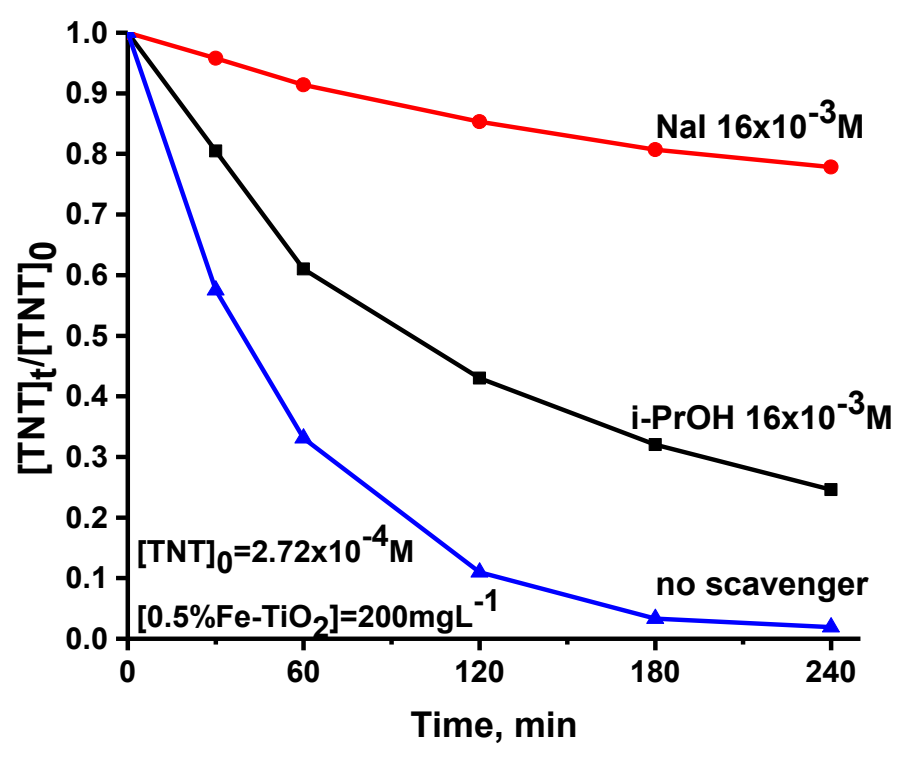

Figure 3. Effect of Nal and iso-propanol on efficiency of TNT photocatalytic degradation

Our findings are supported by the fact that presence of $\mathrm{O}_{2}$ (electron scavenger) inhibited, reductive TNT degradation and pollutant direct photolysis occurs with much lower reaction rate than $\cdot \mathrm{OH}$ radicals mediated process.

\section{Conclusions}

Application of UV-VIS photocatalysis, using $200 \mathrm{mg} / \mathrm{L} 0.5 \mathrm{t} \% \mathrm{Fe}-\mathrm{TiO}_{2}$ catalyst, at $\mathrm{pH}=7$ and 180-240 min irradiation time assures TNT advanced degradation from initial concentrations situated between $(0.27-2.72) \times 10^{-4} \mathrm{M}$.

\section{Acknowledgment}

This work was supported by a grant of the Romanian National Authority for Scientific Research, CNDI UEFISCDI, project number PN-II-PT-PCCA-2011-3.1-0031.

\section{References}

[1] W.D. Won, L.H. DiSalvo, J. Ng, 1976, Toxicity and mutagenicity of 2,4,6-trinitrotoluene and its microbial metabolites, Applied and Environmental Microbiology, 31(4), 576-580

[2] M.Nahem, D.Bahneman, R.Dillert, G.Fels, 1997, Photocatalytic degradation of trinitrotoluene: reductive and oxidative pathways, Journal of Photochemistry and Photobiology A: Chemistry,110(2), 191-199

[3] C.Zaharia, D. Suteu, 2014, A Preliminary Modelling and Optimisation Study of a Homogenous Advanced Oxidation Process Applied for an Industrial Coloured Effluent, Journal of Environmental Protection and Ecology, 15 (4), 1680-1689

[4] Z. M. Li, P.J. Shea, S.D. Comfort, 1998, Nitrotoluene destruction by UV-catalyzed Fenton oxidation, Chemosphere, 36(8), 1849-1865

[5] M.-J. Liou, M.-C. Lu, J.-N. Ohen, 2003, Oxidation of explosives by Fenton and photo-Fenton processes, Water Research, 37(13), 3172-3179 
[6] P.C. Ho, 1986, Photooxidation of 2,4-dinitrotoluene in aqueous solution in the presence of hydrogen peroxide , Environmental Science \& Technology, 20(3), 260-267

[7] S. Hwang, E.J. Bouwer, S.L. Larson, J.L. Davis, 2004, Decolorization of alkaline TNT hydrolysis effluents using $\mathrm{UV} / \mathrm{H}_{2} \mathrm{O}_{2}$, Journal of Hazardous Materials, 108(1-2), 61-67

[8] Z.M. Li, S.D. Comfort, P.J. Shea, 1997, Destruction of 2,4,6-Trinitrotoluene by Fenton Oxidation, Journal of Environmental Quality, 26, 480-487

[9] F.J. Beltran, J.M. Encinar, M.A. Alonso, 1998, Nitroaromatic Hydrocarbon Ozonation in Water. 1. Single Ozonation, Industrial \& Engineering Chemistry Research, 37(1), 25-31

[10 F.J. Beltran, J.M. Encinar, M.A. Alonso, 1998, Nitroaromatic Hydrocarbon Ozonation in Water. 2. Combined Ozonation with Hydrogen Peroxide or UV Radiation, Industrial \& Engineering Chemistry Research, 37(1), 32-40

[11] M.S. Vohra, K. Tanaka, 2002, Photocatalytic degradation of nitrotoluene in aqueous $\mathrm{TiO}_{2}$ suspension, Water Research, 36(1) 59-64

[12] A.R. Ribeiro, O. C. Nunes, M.F.R. Pereira, A.M.T. Silva, 2015, An overview on the advanced oxidation processes applied for the treatment of water pollutants defined in the recently launched Directive 2013/39/EU, Environment International,75, 33-51

[13] L. Petrov, V. Iliev, A. Eliyas, D. Tomova, G. Li Puma, 2007, Photocatalytic properties of modified TiO2 coatings for purification of waste water and air, Journal of Environmental Protection and Ecology, 8(4), 881-909

[14] C. Feng, H. Shang, X. Liu, 2014, Photocatalysis of dinitrotoluene decomposition by $\mathrm{H}_{3} \mathrm{PW}_{12} \mathrm{O}_{40} / \mathrm{TiO}_{2}$ and $\mathrm{H}_{4} \mathrm{SiW}_{12} \mathrm{O}_{40} / \mathrm{TiO}_{2}$ prepared by a modified sol-gel synthesis and solvothermal treatment method, Chinese Journal of Catalysis, 35(2), 168-174

[15] J.F. Zhu, W. Zheng, B. He, J.L. Zhang, M. Anpo, 2004, Characterization of $\mathrm{Fe}-\mathrm{TiO}_{2}$ photocatalysts synthesized by hydrothermal method and their photocatalytic reactivity for photodegradation of XRG dye diluted in water, Journal of Molecular Catalysis A: Chemical, 216(1), 35-43

[16] D. Robert, B. Dongui, J.V. Weber, 2003, Heterogeneous photocatalytic degradation of 3nitroacetophenone in $\mathrm{TiO}_{2}$ aqueous suspension, Journal of Photochemistry and Photobiology A: Chemistry, 156(1-3), 195-200

[17] N. Daneshvar, D.Salari, A.R. Khataee, 2004, Photocatalytic degradation of azo dye acid red 14 in water on $\mathrm{ZnO}$ as an alternative catalyst to $\mathrm{TiO}_{2}$, Journal of Photochemistry and Photobiology A: Chemistry, 162(2-3), 317-322

[18] L.G.Devi, R.Kavitha, 2014, Enhanced photocatalytic activity of sulfur doped $\mathrm{TiO}_{2}$ for the decomposition of phenol: A new insight into the bulk and surface modification, Materials Chemistry and Physics, 143(3), 1300-1308

[19] S.-H. Yoon, J.H. Lee, 2005, Oxidation Mechanism of As(III) in the UV/TiO 2 System: Evidence for a Direct Hole Oxidation Mechanism, Environmental Science \& Technology, 39, 9695-9701 